\title{
Towards the understanding of Chinese collaboration in hospitality - The opinions of professionals
}

\begin{abstract}
The increasingly competitive market in China has resulted in the struggle of hotels for competitive advantage, and even for survival. Among the possible tools to rise above this cutthroat environment is the concept of hotel collaboration. This paper moves towards the understanding of hotel collaboration in China based on the focus group discussions of 22 experienced practitioners in the Chinese hotel and related industries. The data identified several threats, opportunities, and insights into hotel collaboration of domestic with overseas hotels as well as the predictions for the future of this practice in China. Based on specific cultural, political, and economic contexts of contemporary China, the results indicated that partial collaboration is likely to succeed in the hotel market of the country.
\end{abstract}

Key words: China, hotel, collaboration, strategic planning, focus group

$$
\text { 中国酒店 } \square \text { 的合作 } \square \text { 略-一行 } \square \text { 人 } \square \text { 的 } \square \text { 角 }
$$

摘要 :

由于中国酒店行 $\square$ 的 $\square$ 争日 $\square$ 激烈，酒店正 $\square$ 求各种途径以增 $\square$ 自己的 $\square$ 争 $\square \square$ 。其中，酒店合 作在中国 $\square$ 是一个新提出来的策略。本研究的目的就在于了解中国酒店 $\square$ 合作的情况。通 $\square 22$ 位 $\square$ 内人士的小 $\square \square \square$, 得出了几点关于本土酒店与海外酒店合作的机遇、挑 $\square$, 以及未来中国酒 店 $\square$ 合作 $\square \square$ 的 $\square \square$ 。研究 $\square \square$, 基于中国目前的政治、文化和 $\square \square \square$ 境, 酒店 $\square$ 只有部分合作 比 $\square$ 合适。 
关 $\square \square$ : 中国，酒店，合作， $\square$ 略 $\square$ 划，小

\section{INTRODUCTION}

Although the tourism industry in China dates back only to the late 1970s, the industry has grown on a steady pace ever since (Gu, Ryan, \& Yu, 2012). Chan \& Yeung (2009) report that, according to the World Tourism Organization (UNWTO), China will be the world's most visited tourist destination by 2020, receiving up to145 million estimated visitors annually. With the subsequent increase in hotel numbers, from 3,856 to 11,829 between 1999 and 2005, the fast developing market has also encouraged the Chinese government to spur hotel development politically.

While most Chinese hotels previously aimed at servicing overseas guests and addressing political needs (Gu et al., 2012; Zhang, Pine, \& Lam, 2005), the recent growth in numbers and the emerging domestic market have further fuelled the competition among hoteliers. Previous research has shown various issues related to this fast-paced development, such as persisting problems in hotel management (e.g., Chan \& Yeung, 2009; Xu, 2012; Zhang et al., 2005), the use of outdated technology (Kong, 2006), and domestic hotels being constantly outperformed by international chains (Gu et al., 2012; Pine, 2002). China’s recent entry in the WTO has largely removed government control on foreign hotel companies (Pine \& Qi, 2004) and its power over the entry of international hotel chains in the local market. This development has threatened the domestic hotels because Chinese hotel chains are still significantly weaker than their international counterparts (Pine \& Qi, 2004). 
Several local hotels have subsequently searched for support from foreign chains, whereas individually managed hotels have been largely outgrown (Chan \& Yeung, 2009; Gu et al., 2012; Pine, 2002). However, recent political developments, such as a more favorable position for government loans, have provided a new competitive edge to domestic hotels (Gu et al., 2012), which suggests that a wider spectrum of collaboration may be possible among them. To help both policy makers and academics better understand the current situation of hotel development in China, the current research will focus on the issue of hotel collaboration, which is still an underresearched topic.

Due to the substantial lack of literature concerning Western paradigms (Kong \& Cheung, 2009), the most suitable way of gaining contemporary information is the critical analysis of the current perspective of Chinese hoteliers by using focus group analysis. In particular, the goals of this study are thus (1) to investigate and analyze the concept of hotel collaboration in Mainland China as perceived by industry practitioners and (2) to identify perceived related opportunities and threats. In order to fully reach the aim of this study, several questions need to be asked, namely (1) how do practitioners perceive the future of hotel chains and collaboration in China, (2) how do they understand collaboration with overseas hotels, (3) how do they relate the growing domestic market to hotel collaboration, (4) what are generally perceived collaboration related threats and opportunities in China, and last (5), which form of hotel collaboration practitioners perceived to be the most suitable for a Chinese context. The understanding of a Chinese hotel practitioners' point of view on hotel collaboration in China will not only enrich the scarce body of literature on the concept, but ultimately give a valuable contribution for practitioners interested in the Chinese hotel market.

\section{LITERATURE REVIEW}




\section{Current situation of the Chinese hotel market}

The increasing competition in the Chinese hotel market has given birth to an unforgiving situation particularly for local hotels. The entry in the WTO broke the last boundaries for the entry of international hotel chains, and the rapid growth of domestic hotels has further spurred competition (Chan \& Yeung, 2009; Pine \& Qi, 2004). In particular, Chinese hoteliers who are running smaller businesses have shown their concern on how they will effectively compete with the more professional, financially stronger, and better-managed foreign hotel chains (Hung, 2013).

As a response to the increasing threat of competition, several Chinese hotels have decided to cut costs, a move that has further lowered the already struggling service quality (Chan \& Yeung, 2009). Chinese generation Y employees tend to be less obedient than older generations, while the comparatively low salaries and little social appreciation attached to hospitality work have also negatively influenced service (Hung, 2013). According to Hung (2013), hotels do not only lack “software” (i.e. service quality), but also appropriate management skills.

Chan and Yeung (2009) highlight an array of related issues involving Chinese hotels. Given the relatively short time span of developing the domestic industry, Chinese hotels generally lack the managerial experience of foreign chains. This situation has resulted in the ever-growing problems of managing local staff and the lack of coordination among different hotels (Chan \& Yeung, 2009). Poor knowledge on reservation systems, marketing strategies, property management systems, cost control, and human resources development has further complicated the situation and placed local hotels in an unfavorable position (Xu, 2012; Zhang et al., 2005). Although there have been thoughts of attracting more experienced managers for 
Chinese-run hotels, Gu et al. (2007) suggest that this strategy is still very difficult for most domestic hotels because of financial reasons.

On a higher level, Chinese hoteliers perceive government management as insufficient and inadequate (Hung, 2013). Government bodies are criticized for the lack of appropriate management skills and the lack of vision on the future development of Chinese hotels (Hung, 2013). However, government involvement has spurred an excessive boom in hotel development in the country's eastern regions, while still highly neglecting the west. Other contextual factors have created a difficult environment for Chinese hotels. These factors include perceived civil instability, transmitted disease, corruption, hyperinflation of cost, crime, possible hostility from other nations, food safety, inability to deal with crises, and the lack of technology (Chan \& Yeung, 2009; Hung, 2013).

Nonetheless, several strengths and opportunities for Chinese hotels have been identified. Gu et al. (2007) highlight that, although still struggling, service quality has improved notably during the last years because of the experiences with overseas tourists and the increasing numbers of foreign contacts. International involvement has substantially helped improve the domestic industry in terms of service quality, management know-how, and capital. This improvement has also been aided by the economic growth of China and the increasing number of Chinese people travelling to and learning from hotel services abroad (Hung, 2013).

Hung (2013) emphasizes that the government is increasingly supporting hotels by improving infrastructures, such as roads and airports. Improvement in infrastructures eases the travel to reach more remote destinations within China. Chinese hoteliers have also perceived events, such as the Shanghai World Expo in 2010 and the successful Beijing Olympics in 2008, to inspire further confidence and increase government trust. Further opportunities have been 
identified as Chinese hoteliers raising capital in the overseas equity markets, the government giving favorable credit opportunities, and ultimately promoting better knowledge of Chinese culture and management practices (Gu et al., 2012; Pine \& Qi, 2004).

Hotel collaboration can be an opportunity for Chinese hotels in the future (Hung, 2013). Chinese hoteliers have highlighted that hotel collaboration is a current phenomenon for smallscale hotels to merge with larger, mainly Western, hotels, to gain competitive advantage. The global financial crisis in North America and Europe has raised questions whether the future will see more collaboration among domestic hotels rather than only a look to the West. The lack of related research makes significant the investigation and the analysis of the concept of hotel collaboration in Mainland China to identify future possibilities and related issues.

\section{Hotel collaboration}

There are several forms of hotel collaboration found in the contemporary hospitality industry. Arguably, the most popular form is hotel franchising.

Franchising is based on a two-party relationship between the franchisor and the franchisee. The franchisor offers an array of operational know-how, a successful operational system (i.e., trademark or corporate image), assistance in various areas, easier market access, lower costs, and other related advantages to the franchisee (Hall \& Dixon, 1988). In exchange, the franchisor can expand rapidly, effectively, and with minimal capital involvement (Cherkasky, 1996; Pine, Zhang \& Qi, 2000). Across the hotel sectors, franchising has been a highly effective business practice with 65\% of the US-hotel rooms franchised as of 1997 (Rushmore \& Araza, 1997). 
The concept of franchising was introduced only in the 90's in China, and is still a fairly new concept (Xiao, O’Neill \& Wang; 2008). The changes in the Chinese hotel industry to have more privately owned hotels have opened the door for a franchising possibility. Nevertheless, the question is if the concept can be effectively applied to the Chinese cultural and business context (Pine et al., 2000). Moreover, literature still lacks an investigation of the opinions of local hoteliers (Xiao et al., 2008).

Other increasingly popular forms of hotel collaborations include co-branding, jointbranding, and brand-alliances, which are all based on brand extension (Guillet \& Tasci, 2010). An example of brand extensions is to possibly unite a restaurant and a hotel under one brand. A study of Guillet and Tasci (2010) in the Chinese context indicates a possibility for Chinese hotels to extend their brands, but there is still a lack of awareness and practical application of this form of collaboration. Nonetheless, the study was conducted from the perspective of Chinese consumers, but the point of view of the industry did not emerge from its results.

In 2011, Wang reports that indigenous hotel groups owned 1,680 hotels, although hotel collaboration in China originated from foreign chains entering the country. The main forms of collaboration that emerged in the country are purchasing, franchising, or other forms of contracting mainly smaller hotels (Wang, 2011). However, a big gap was observed in the performance of foreign and domestic franchisors and the success of their collaboration. The empirical investigation on the concept of hotel collaboration in a Chinese context from a practitioners' perspective is still scant, and the future of the concept in China is uncertain. Therefore, this study attempts to address this gap in research and in literature.

\section{METHODOLOGY}


This study employed focus groups to investigate and to analyze the concept of hotel collaboration in China as perceived by industry practitioners. As an efficient qualitative method, a focus group is a quasi-formal or formal instance (e.g., conversations, group discussions, and negotiations) that produces a large amount of data seldom generated by individual interviews. Focus groups contribute particularly powerful insights into norms and collective assumptions (Denzin \& Lincoln, 2005), and provide the researcher with in-depth understanding of the topic discussed (Edmunds, 1999).

The focus groups were conducted in the beginning of 2013 in Hangzhou (China) with 22 practitioners from various hotels in Mainland China. Focus groups that exceed 10 participants are difficult to moderate, and limit the input possibilities for participants (Barbour \& Kitzinger, 1999). Hence, the 22 participants were randomly divided into 3 groups, with 9, 7, and 6 members. All 22 members were Mainland Chinese practitioners in the hotel industry and were studying in a hospitality and tourism Master’s program offered by the Hong Kong Polytechnic University in Hangzhou. All the focus groups were conducted simultaneously in an outpost center in Zhejiang University, where the Master's program was offered. Three students were asked to moderate the respective focus groups, which were held simultaneously. Before the sessions, the moderators were shortly trained by the class instructor, which is one of the authors of this study. The purpose of this training was twofold; first (1) the moderators were reminded to use research techniques which they had previously studied in their research method course and second (2), the importance to stimulate involvement of all participants was underlined. The moderators were also provided with a structured questionnaire which, although given as a guideline rather than a rigid pattern, was applied for all three focus groups. 
Out of the 22 participants, the average working experience in the Chinese hotel industry was 11.4 years, ranging from a minimum of 1 year to a maximum of 28 years. The average age of the participants was 35.6 years, ranging from a minimum of 26 to a maximum of 50. Eight of the focus group members were general managers, ten were managers, three were assistant managers from different hotel departments, and one was a chef and hospitality educator. Twelve of the participants were male, whereas the remaining ten were female (see Table 1)

\section{INSERT TABLE 1 APPROXIMATELY HERE}

Holly (1999, p. 88) suggests that in order to best report the findings of a focus group, the researcher "pulls and together similarities and differences between the groups and ties the findings back to the overall research objectives of the study.” As the focus group discussions were audio recorded and later transcribed, the results were coded according to the most significant themes that emerged in relation to hotel collaboration in Mainland China. However, individual speakers cannot always be identified from the recording because the transcript has been translated from Chinese to English, and thus, the frequency count could possibly be misleading (Krueger, 1998). Therefore, the contents of different focus groups were compared with the themes and not with the frequency of comments, which proved to be successful in previous studies that had applied focus group techniques in similar contexts (e.g., Hung, 2013). As literature on the topic was found to be limited and this study is mostly exploratory, data was coded mostly inductively as suggested by Hennink, Hutter and Bailey (2011). In other words, themes were identified as they were raised by the relevant focus groups respondents and the obtained data was taken as the main source of information. The lead author was largely responsible for the initial coding, while the data was triangulated by one of the co-authors in 
order to guarantee reliability and validity of the research findings. The qualitative research software Nvivo was used by both researchers throughout the process of data coding and analysis.

\section{FINDINGS}

The participants provided substantial amounts of valuable information regarding their perception on hotel collaboration in China in terms of opportunities, threats, collaboration with foreign/overseas hotels, and the future of hotel collaboration in Mainland China. The information has been coded into the core topics that emerged during the sessions.

\section{Opportunities for hotel collaboration in Mainland China}

The participants view the collaboration between domestic and foreign hotels as a major opportunity. Domestic hotels are confirmed to lack good management ideas, innovative and effective training methods, know-how of the management process, branding and marketing knowledge, as well as effective operation systems. Collaboration is mentioned to be potentially beneficial for both domestic and foreign hotels in China.

For domestic hotels, collaboration with foreign hotels is a good learning opportunity. In general, foreign hotel managers are thought to be more knowledgeable in most domains where Chinese hotels lack competitiveness. Corporate culture is still a foreign concept for most domestic hotels, and particularly, smaller hotels are struggling to adapt to it. Moreover, branding is a topic where many local hotels are considered not to be sufficiently competitive. According to the participants, marketing and branding inputs are among the most valuable contribution assets for Chinese hotels. In particular, one respondent stated that "foreign hotels are doing better in management, innovation, service quality and corporate culture, so domestic hotels can learn from them through collaboration”. 
On the other hand, foreign hotels often lack the necessary know-how skills to survive in the Chinese market and to cope with the Chinese customers. Several foreign hotels have failed to establish fundamental and highly needed relationships with the Chinese government. One participant stated that in particular "domestic hotels are outperforming foreign investors by getting loans from the government and having a better relationship with the government in general". In addition, the food and beverage services offered by overseas brands often do not conform to Chinese tastes and standards and domestic hotels "do in general better understand the needs of domestic guests”. Another opportunity therefore arises, which is the need for foreign hotels to gain more insights into the Chinese culture. One participant raised that this is " $a$ mutually beneficial relationship", as this asset is seen as highly needed to survive in the Chinese market.

Threats for hotel collaboration in Mainland China

Most focus group participants perceive that the main threat to successful hotel collaboration is the characteristic of Chinese culture.

Accordingly, collaboration in business is a difficult concept for most Chinese people. Given that the hotel market in China is highly competitive, one participant stated that "intellectual property is highly valued, which often leads to mistrust and reluctance on sharing information among hoteliers". Subsequently, many domestic hotel owners do not agree on sharing business strategies because of their fear to be copied or sabotaged. In addition, entrepreneurs in China are stubborn and not open to compromises related to different ideas from their partners. A respondent explained that in particular "hotel bosses usually want to keep their money for themselves instead of sharing it or giving it to management companies". Especially the owners of private enterprises in China are highly profit-oriented and greatly value short-term 
gain. According to the participants, as long as domestic hoteliers earn money, it is unlikely that they will willingly use a part of it to invest into future gain.

When collaborating with Western hotels, Chinese hotels face major cultural issues, particularly in human resources. Development strategies of foreign hotels and corporate culture are usually new concepts for Chinese hoteliers and employees. If domestic hotel workers cannot blend with the system, they will easily feel marginalized, which frequently leads to unwillingness to collaborate and lack of motivation. Accordingly a participant mentioned that "it is difficult for Chinese employees working in domestic hotels to get used to western brands, no matter their culture or management style. It takes a long time for them to adapt".

Furthermore, the participants reveal that most Chinese employees who can adapt to a foreign management style in a domestic hotel will rather look directly for a job in a foreign hotel. This choice, which is motivated by higher salaries and better working conditions, further increases the competition between domestic and foreign hotels instead of collaboration. According to the participants, collaboration is thus hindered by "a general human resource problem".

Most Western hotels experience difficulty dealing with the flexible style of Chinese hotels' management, and thus, successful collaboration has been challenging. Several domestic hotels are also run by real estate agencies, which care more about government connections than increasing service quality and making money. According to the participants, collaboration between overseas and domestic hotels may cause a possible conflict of interest and thus "choosing a suitable partner for collaboration is vital",

Collaboration with foreign/overseas hotels 
Although collaboration with foreign hotels is seen as a major learning opportunity for both domestic and foreign hotels, the participants express that the success is highly dependent on the context where collaboration takes place.

Generally, foreign hotels tend to have good locations, such as bigger cities. In addition, a considerable amount of money has been spent on marketing and branding, which are assets most Chinese hotels lack, and can only be gained through collaboration. Moreover, booking overseas hotels will be easier for guests because they usually have sophisticated management software, which creates trust from the customers because of fair hotel rates. One participant mentioned that "domestic hotels change their rates according to the market, while foreign hotels usually have fixed room rates". Therefore, collaboration with foreign hotels can be useful in gaining trust and improving the brand for domestic hotels.

The participants view collaboration with foreign hotels as suitable in pleasing business tourists. However, several domestic hotels lack "service quality," which is a central requirement for tourists. Collaboration among domestic hotels is more favorable for conferences because, according to a participant, "domestic hotels know better how to be flexible in different conditions and circumstances". Domestic hotels also are believed to know how to entertain Chinese customers and generally understand these customers' needs better. Therefore, the collaboration of domestic hotels with foreign hotels can result in each party benefitting from knowledge sharing.

The government is perceived as a critical point in collaborating with foreign hotels. Domestic hotels know how to approach the Chinese government, whereas foreign hoteliers, even if collaborating with domestic hotels, tend to stick closely to their rules and policies. This practice is not been favored by the government authorities. A participant stated that, in order for 
hotel collaboration to succeed, "there is a need for government involvement as well as relationships with the hotel association". Collaboration with foreign hotels can therefore be a hindrance for domestic hotels in terms of flexibility and relationship with the authorities. According to the participants, it is therefore up to the priorities of every individual hotel if opting for a foreign collaboration can be an advantage.

Future of hotel collaboration in Mainland China

Most participants agree that the growing trend of collaboration between hotels in China exists. However, these participants are skeptical whether this collaboration will lead to the dominance of hotel chains in the Chinese market.

One participant states that "hotel chains operate only one-fifth of the domestic and foreign hotel market". This trend is likely to increase because of the relative ease in opening hotels in China. Hence, lower quality hotels are outperformed and have to consider going out of business if they do not opt for collaboration. This tendency will likely be intensified with the growth of hotel numbers in China and the increasing need for competitive advantage.

While undeniably a global trend, the participants believe a future dominance of hotel chains on the Chinese market is highly unlikely. Accordingly, if individual hoteliers learn to manage their hotels more effectively, they can develop their own specific products that will suit the individual needs of customers better than the less flexible hotel chains. In addition, several locals have learned and are still learning from international brands, and are applying and improving this knowledge to their own businesses steadily.

The participants suggest that the future of the Chinese hotel market will probably lie in partial collaborations and total collaboration will be excluded in the specific context of China. 
One respondent mentioned that "full collaboration like in many western markets is highly unlikely to be a future trend in China". could the participants suggest collaboration in one specific aspect, such as branding, while autonomy in other sectors is still granted for individual hotels. The particular cultural traits of the Chinese people, such as a general lack of trust and unwillingness to collaborate, will hinder the future of intense hotel collaboration and will only favor partly hotel collaboration.

Furthermore, politics has been mentioned as a determinant for the future of hotel collaboration in China. Hence, a higher degree of collaboration, if favored by government regulations, will possibly succeed. If this is not the case, the future of the industry will be different. The participants highlight that the special political situation in Mainland China makes the involvement of the government a key factor in the future of the Chinese hotel industry. This situation is believed to be particular to China and not a main concern in most western countries.

\section{DISCUSSION AND IMPLICATIONS}

Although the hotel practitioners acknowledge the global trend of hotel collaboration, they still view the future of intense hotel collaboration within Mainland China skeptically. 
Figure 1: Professionals' view of Chinese hotel collaboration

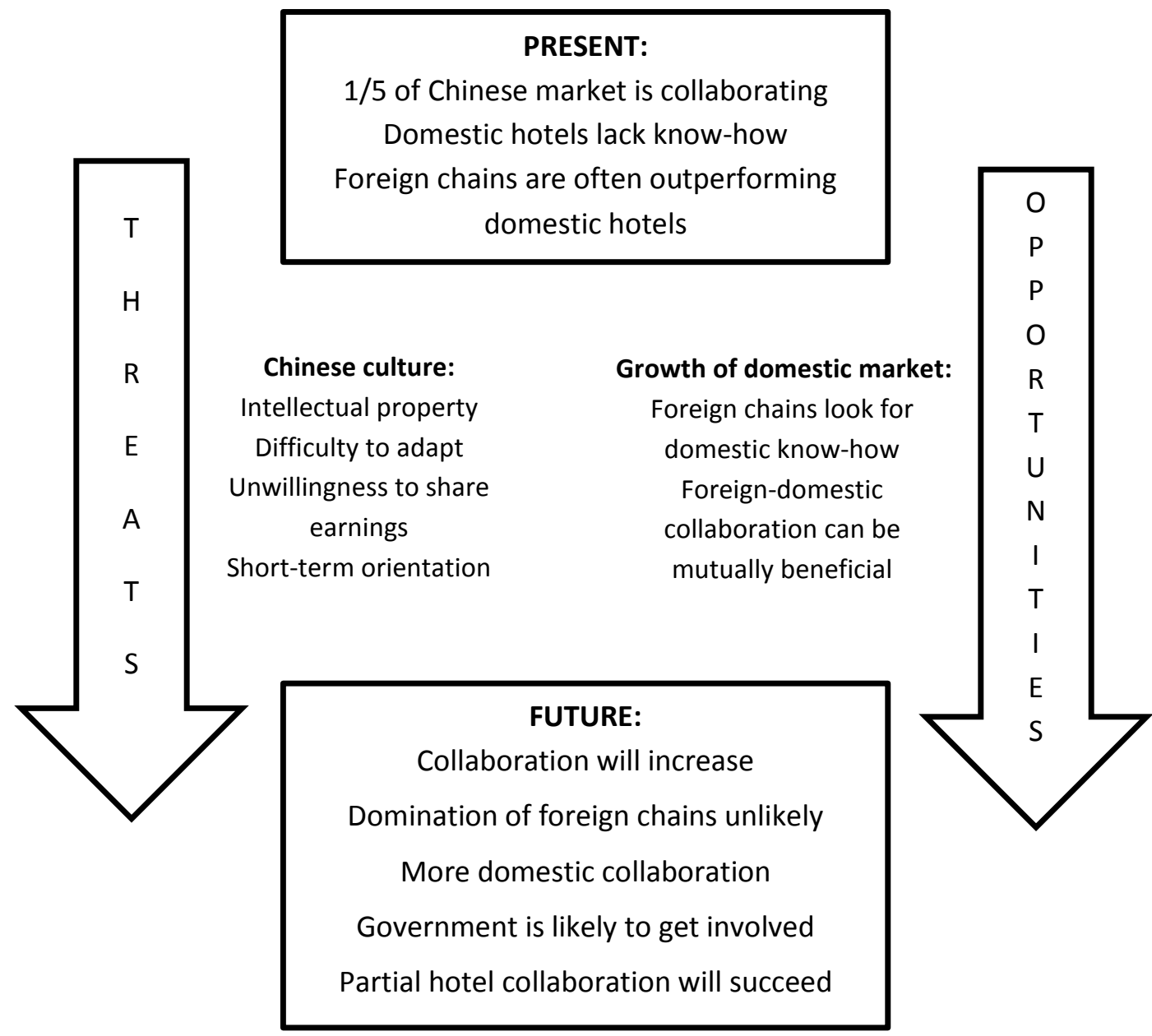

The Chinese culture is considered as the main determinant in this process. According to the respondents, Chinese hoteliers are usually reluctant in business collaborations because of the highly competitive environment, fear for intellectual property loss, and unwillingness to invest in projects with long-term gain.

The findings correlate with the underlying assumptions of Chinese organizational culture that has been identified by Kong (2006), namely, (1) an ever hostile word, (2) self-seeking individuals, and (3) hierarchical social reality. The belief of an ever hostile world reflects the common belief that the "environment is so hostile and unpredictable, with all social participants 
always on the look-out to dominate, cheat and make use of the unvigilant or unguarded” (Kong, 2006, p. 368). The beliefs result in highly self-interested individuals who put their own benefit in the highest level of importance. Moreover, this belief has given birth to a particular social hierarchy that is meant to protect personal interests through a selective enforcement of rules. Therefore, an outsider of an organization is forced to go through a tedious process of adjustments because flexibility is often not granted (Kong, 2006). If this understanding is not reached, collaboration in a Chinese context is likely to fail (Gu et al, 2007; Pine \& Qi, 2004).

The participants also mention that the hotel practitioners in China tend to be stubborn, do not want to adapt their practices to other hotels, keep their own way of making business, and are generally reluctant to compromises. These responses correlate with the observation of Pine and Qi (2004) that many domestic hotels do not value new ideas and lack vitality and sensitivity to business environments and market changes. Especially in branding, corporate culture and innovation are often seen as unnecessary. The observation of Chan and Yeung (2009) that costcutting among domestic hotels (including salaries) results in the decreasing service quality, confirms the barrier in effective hotel collaboration in China.

Particular to the Chinese context, the view of participants that the Chinese government is a key figure in the future of hotel collaboration confirms previous findings by Hung (2013). Although China's administration and business systems seem chaotic to most outsiders (Chan \& Yeung, 2009), most local entrepreneurs know how to deal properly with government regulations. Foreign establishments, especially overseas hotels, are mentioned as being "quite rigid" in their business mentality, which is a trait disliked by local authorities. The better relationship between domestic hotels and the local government is therefore a possible barrier to future international collaborations. 
While in the past, foreign hotels had enjoyed more favorable credit conditions (Pine \& Qi, 2004), a recent development has put domestic hotels into a better position (Gu et al., 2012). Although the participants mention that this development could inspire international hotels to look for a higher degree of collaboration with domestic hotels, this development in combination with the Chinese cultural traits is likely to influence negatively future hotel collaboration.

Nonetheless, participants identify several possibilities for the growth of hotel collaboration in China. A major concern is the lack of hardware and software in domestic hotels. This issue is in line with previous research that highlighted the lack of service quality, training programs, management, technology, and capital in domestic hotels (Gu et al., 2012; Hung, 2013; Kong, 2006). According to the hotel practitioners, collaboration with foreign hotels can possibly increase the level of competitiveness of Chinese hotels. According to Cai (2004), marketing and branding are major shortcomings of domestic hotels that foreign collaboration can overcome.

International hotels are believed to be searching for future collaborations with domestic hotels. Although they have been outperforming domestic hotels in the past (Pine \& Phillips, 2005), the participants reveal that many foreign brands are losing advantage because they do not have the knowledge on how to entertain local guests, do not understand the local culture, and do not know how to deal with the authorities properly. Literature has shown examples of major Western hotel chains, such as the Marriot and Hilton, that suffered major losses because of the misunderstanding of local culture and management practices (Gu et al., 2012; Huimin \& Ryan, 2011). This finding confirms earlier theories that Chinese management will not entirely follow Western concepts, but rather will develop its own context-specific form (Fan, 1998). Chinese customers have become more critical and do not accept foreign brands as religiously as they used to (Gu et al., 2012), while more Chinese brands enter the market (Ewing, Windisch \& Newton, 
2010). This situation might inspire foreign brands to look for a deeper relationship with domestic hotels and eventually spur collaboration.

Generally, hotel practitioners agree that hotel collaboration in Mainland China will be difficult, and only partial collaboration will have success in the future. However, the total dominance of hotel chains in China, as foreseen by Pine and Qi (2004), is believed to be questionable.

Chinese hotels have gained a sustainable amount of know-how and enjoy benefits from the government (Gu et al., 2012). The participants confirm that most of them will not look for a high degree of multinational collaboration in the future. The practitioners believe that the concept of "partial hotel collaboration" (e.g., only in one or several sectors), is likely to succeed in China. Chinese hotels are looking for more domestic collaborations because the success of Chinese hotel chains (Gu et al., 2012) is favored by the better understanding of the growing number of domestic tourists.

\section{CONCLUSION}

The Chinese hotel business has been growing rapidly and steadily during the past years. China was forecasted to be the main tourist inbound destination as early as 2010. To stay competitive in this increasingly aggressive environment, hotels have to look for new business models, such as hotel collaboration. To investigate the applicability of this concept to the specific situation of China, hotel practitioners were asked to participate in focus groups to give insights to the under-researched topic of hotel collaboration.

Based on the specific cultural, economic, and political contexts of Mainland China, Chinese hoteliers believe that only partial hotel collaboration can succeed in the future of the 
industry. Chinese culture, political practice, and the economic situation of China are identified as the main determinants of this development in the hotel industry. This leads to several theoretical and practical contributions which are offered by this study. From a theory standpoint, the application of hotel collaboration in a Chinese cultural, economic and political context is not widely understood. By investigating the viewpoints of experienced Chinese hotel practitioners in regard, a new theoretical insight on the related possibilities, issues and possible future directions is offered. In particular, the notion of partial collaboration among lodging industries in China has emerged as a new focus of interest. The theoretical contributions of this research also lead to several practical implications. First, past studies have shown that especially foreign hotel chains had difficulties in surviving on the Chinese market, while domestic hotels were often desperately looking for survival by searching for overseas' collaboration. The findings of this study offer an insight on collaboration possibilities for domestic hoteliers and foreign hotels alike. It also highlights that understanding the Chinese cultural, political and economic context is a vital prerequisite for entering the China hotel market through collaboration. While hotel chains are often expected to dominate the market in the future, caution for practitioners is advised in a Chinese context and the concept of partial collaboration is offered as a possibility for competitive advantage.

The current study acknowledges several limitations. First, the participants of the focus groups were selected by using a convenience sample. Although they were all experienced in Chinese hotel industry, the random sampling technique could have been more suitable to make the results more presentable. Second, the results mainly focused on the practitioners' perception of hotel collaboration in China. Focusing more on developing recommendations could have enhanced the practical applicability of the results. Last, the respondents were not asked to 
compare the Chinese hotel development with their counterparts in other countries. Therefore, the participants might not have sufficient knowledge of the international hotel industry. By comparing with other countries, a comparative study could have highlighted the particular situation in China to understand its position in the global hotel market.

Last, this research also offers possibilities for future research. Follow-up studies are advised to look at the newly emerged concept of partial hotel collaboration and its' implications for the Chinese context. This could be done by looking into Chinese case studies where hotel collaboration in a specific sector is found and collect information on its practical success. Also, partial hotel collaboration among western hotels could be scrutinized and a comparison to the specific cultural, political and economic context of China could be drawn. Next, this study only looked at perceptions of Chinese hotel practitioners and did not consider a policy perspective in regard of hotel collaboration in China. This could be done by investigating specific regulations and policies in regard and whether or not there has been any recent related development. Also, managing bodies of hotel chains which have entered or attempted to enter the Chinese market could be interviewed in order to gain a deeper understanding of these issues. Last, collaboration among companies in other sectors of the Chinese economy could be compared to collaboration among hotels and related findings could offer more insight on how the industry is likely to develop. 


\section{REFERENCES}

Barbour, R., \& Kitzinger, J. (Eds.). (1998). Developing focus group research: politics, theory and practice. London: Sage.

Cai, L. A. (2004). State-owned economy and budget hotels in China-from commodity to brand. Asia Pacific Journal of Tourism Research, 9(1), 29-42.

Chan, B., \& Yeung, S. (2009). Hotel Development in China: The Hoteliers' Perspective: 酒店从 业员对中国酒店业发展的看法. Journal of China Tourism Research, 5(2), 210-223.

Cherkasky, W. B. (1996). Franchising: a key to business success. Franchising Research, 3(5), 57.

Denzin, N. K., \& Lincoln, Y. S. (Eds.). (2005). The Sage handbook of qualitative research. Sage Publications, Incorporated.

Edmunds, H. (1999). The focus group research handbook. Chicago: NTC Business Books.

Ewing, M. T., Windisch, L., \& Newton, F. J. (2010). Corporate reputation in the People's Republic of China: A B2B perspective. Industrial Marketing Management, 39(5), 728736.

Fan, Y. (1998). The transfer of Western management to China: Context, content and constraints. Management Learning, 29(2), 201-221.

Gu, H., Ryan, C., \& Yu, L. (2012). The changing structure of the Chinese hotel industry: 19802012. Tourism Management Perspectives, 4, 56-63.

Guillet, B. D., \& Tasci, A. D. (2010). Travelers’ Takes on Hotel—Restaurant Co-Branding: Insights for China. Journal of Hospitality \& Tourism Research, 34(2), 143-163.

Hall, P., \& Dixon, R. (1988). Franchising. London: Pitman.

Hennink, M., Hutter, I., \& Bailey, A. (2011). Qualitative Research Methods. Sage Publications: UK. 
Holly, E. (1999). The focus group research handbook. Lincolnwood, IL: NTC Business Books and American Marketing Association.

Huimin, G., \& Ryan, C. (2011). Ethics and corporate social responsibility-An analysis of the views of Chinese hotel managers. International Journal of Hospitality Management, 30(4), 875-885.

Hung, K. (2013). Understanding China's Hotel Industry: A SWOT Analysis 中国酒店业的 SWOT 分析. Journal of China Tourism Research, 9(1), 81-93.

Kong, H., \& Cheung, C. (2009). Hotel development in China: a review of the English language literature. International Journal of Contemporary Hospitality Management, 21(3), 341355.

Kong, S. H. (2006). An empirical investigation of mainland Chinese organizational ideology. Asian Business \& Management, 5(3), 357-378.

Krueger, R. A. (1998). The focus group kit 6: Analyzing \& reporting focus group results. Thousand Oaks: Sage Publications.

Pine, R. (2002). China's hotel industry: serving a massive market. The Cornell Hotel and Restaurant Administration Quarterly, 43(3), 61-70.

Pine, R., \& Phillips, P. (2005). Performance comparisons of hotels in China. International Journal of Hospitality Management, 24(1), 57-73.

Pine, R., \& Qi, P. (2004). Barriers to hotel chain development in China. International Journal of Contemporary Hospitality Management, 16(1), 37-44.

Pine, R., Zhang, H. Q., \& Qi, P. (2000). The challenges and opportunities of franchising in China’s hotel industry. International Journal of Contemporary Hospitality Management, 12(5), 300-307. 
Rushmore, S., \& Araza, S. (1997). Hotel franchising: how to be a successful franchisee. Real Estate Finance Journal, 13, 51-57.

Wang, Y. (2011). The management of and indigenous hotel chain company in China: A case study of Sichuan Minshan Hotel Corporation. UNLV Thesis, Paper 1106.

Xiao, Q., O’Neill, J. W., \& Wang, H. (2008). International hotel development: A study of potential franchisees in China. International Journal of Hospitality Management, 27(3), 325-336.

Xu, J. (Ed.). (2012). A history of the Chinese hospitality industry. Beijing: China Tourism Press.

Zhang, H. Q., Pine, R., \& Lam, T. (2005). Tourism and hotel development in China: From political to economic success. London: Routledge. 